\title{
Article \\ Analyzing the Effects of Heat Treatment on SMAW Duplex Stainless Steel Weld Overlays
}

\author{
Bernard-Maxmillan Sim ${ }^{1, *(\mathbb{C})}$, Sai-Hong Tang ${ }^{1, *}$, Moath Alrifaey ${ }^{1,2}$ and Edwin-Nyon Tchan Jong ${ }^{3}$ \\ 1 Faculty of Engineering, University Putra Malaysia, Serdang 43400, Malaysia; eng.alrifaiy2005@gmail.com \\ 2 Department of Mechanical Engineering, Faculty of Engineering Technology and Built Environment, \\ UCSI University, Taman Connaught, Kuala Lumpur 56000, Malaysia \\ 3 Faculty of Engineering and Science, Curtin University of Malaysia, Miri 98000, Malaysia; \\ edwinjong@curtin.edu.my \\ * Correspondence: bernard_sim@yahoo.com (B.-M.S.); saihong@upm.edu.my (S.-H.T.); \\ Tel.: +60-38-946-6332 (S.-H.T.)
}

Citation: Sim, B.-M.; Tang, S.-H.; Alrifaey, M.; Tchan Jong, E.-N. Analyzing the Effects of Heat Treatment on SMAW Duplex Stainless Steel Weld Overlays. Materials 2022, 15, 1833. https:// doi.org/10.3390/ma15051833

Received: 3 July 2020

Accepted: 24 August 2020

Published: 1 March 2022

Publisher's Note: MDPI stays neutral with regard to jurisdictional claims in published maps and institutional affiliations.

Copyright: (c) 2022 by the authors. Licensee MDPI, Basel, Switzerland. This article is an open access article distributed under the terms and conditions of the Creative Commons Attribution (CC BY) license (https:// creativecommons.org/licenses/by/ $4.0 /)$.

\begin{abstract}
Duplex stainless steel (DSS) has a reasonably high resistance to chloride stress corrosion cracking for offshore and marine applications. However, DSS weld overlay has not been successfully demonstrated due to some inherent problems in achieving pitting and crevice corrosion resistance. In this research work, isothermal heat treatments $\left(350,650\right.$ and $\left.1050{ }^{\circ} \mathrm{C}\right)$ with and different cooling rates have been performed DMR249 Grade A by using shield metal arc welding (SMAW) with an E2209 electrode. Micrographs have shown two phase microstructures of the DSS weld metal, the amounts of austenite phase increased with increment of post-weld heat treatment (PWHT) temperatures. The dilution has maintained consistent values except solution annealing that has shown the disappearance of the heat affected zone in micrographs. The weld metal hardness values increased with PWHT temperatures and remained low at solid solution annealing temperatures. The major alloying elements (C, Mo, Cr, Ni, N, and Fe) were analyzed, as these elements can contribute to intermetallic phases. The results showed that $\mathrm{C}$ and $\mathrm{Cr}$ content slightly increased with PWHT except for solid solution annealing, Mo showed consistently low content due to dilution effects. Ni maintained higher content, although the heat-treated samples showed slight fluctuations. Nitrogen produced consistent values, as recommended to prevent critical involvement in nitride precipitation.
\end{abstract}

Keywords: duplex stainless steel; dilution; chemical composition; solidification; microstructure and microhardness

\section{Introduction}

In the petrochemical and oil \& gas industries, most corrosion-resistant alloy weld overlays are clad with austenitic stainless steel or high nickel alloys. Duplex stainless steel (DSS) offers better economics for its better resistance of pitting corrosion and the ability to maintain good mechanical properties as compared to other stainless steels [1]. DSS weld overlays have not been successfully demonstrated due to some inherent problems to achieve resistance to pitting and crevice corrosion caused by the intermetallic precipitations in the heat-affected zone. DSS is typically manufactured in annealed conditions because it has a high content of alloying elements, such as chromium, molybdenum, and nitrogen. Their structures are generally consisted of austenite $(\gamma)$ (face-centered cubic structure) and ferrite (body-centered cubic structure) [2]. An alternative method to improve the material's pitting corrosion resistance with reliable and affordable cost is using corrosion resistant alloy (CRA) cladding, whiech has been demonstrated to be more cost effective, considering the higher strength, better long-term reliability and light weight [3].

CRA weld overlays are formed through a process in which one or more metals are fused or joined to form a complete corrosion-resistant alloy protective layer on the surface of the substrate material. This weld overlay is chemically and/or metallurgically bonded 
to the base metal with a consistent composition alloying element interface between the corrosion-resistant alloy and the carbon steel substrate [3]. The term weld overlay designates the application of a relative thickness layer with at least $3 \mathrm{~mm}$ as recommended by industry practitioners. The corrosion resistance of weld deposits is strongly dependent on the amount and nature of the chemical elements and heat cycles. The shield metal arc welding (SMAW) process is the most common and is a basic welding process being recognized in all industries. This welding process is relatively simple, low cost and adaptable to any confined space and can be carried out remotely. Heat treatment for DSS weld overlay on low alloy carbon steel substrate has not presented in any industry welding standards. Most of the industrial welding codes only cover for individual groups of material [4,5]. Consequently, the behavior and material properties of CRA weld overlays are less understood as compared to other steels. In particular, the effect of PWHT on DSS weld overlays and the low alloyed carbon steel substrates under hydrogen $\left(350{ }^{\circ} \mathrm{C}\right)$, stress relief $\left(650{ }^{\circ} \mathrm{C}\right)$, and solution annealing $\left(1050^{\circ} \mathrm{C}\right)$ are unknown. The aim of this paper is to determine the effect of post-heating on the chemical dilution, microhardness, and microstructure of a DSS E2209 weld overlay.

\section{Materials and Methods}

A medium-strength low-alloy carbon steel DMR 249 Grade A steel plate with dimensions of $450 \mathrm{~mm} \times 450 \mathrm{~mm} \times 20 \mathrm{~mm}$ was used in this research study. This material is commonly used in a wide range of general industries due to its strength, good weldability, low cost, and high availability. Welding consumable E2209-16 @ 4.0 mm was selected to join standard DSS materials, as it offers excellent corrosion resistance to pitting and stress cracking in aqueous chloride applications and offshore environments [6]. Table 1 lists the chemical elements, the materials, and the welding consumable used in this study. A flat welding position was selected because simple and straight forward, the limitation of position produces deeper penetration due to gravity acceleration and it has the significant impact to the characteristic to weld motel pool and output of geometry. The welding parameter process shown in Table 2 was carefully studied to minimize the secondary phases in order to improve pitting corrosion resistance and maintain good bonding strength. Heat input with moderate cooling rates is recommended to ensure that the austenite phase formation is sufficient to achieve corrosion-resistant properties. As reported by Maria et al., higher heat input would result in very slow cooling rates that were favored in the precipitation of sigma phase as evidenced by X-ray powder diffraction (XRD) [7].

Table 1. Chemical elements for base metal and consumable welding.

\begin{tabular}{cccccccccccc}
\hline \multirow{2}{*}{ Materials } & \multicolumn{1}{c}{ Element of Alloy (wt.\%) } \\
\cline { 2 - 11 } & $\mathbf{C r}$ & $\mathbf{C}$ & Mo & Ni & Mn & Ti & Nb & Cu & Si & N \\
\hline Electrode, E2209-16 @ 4 mm & 23.49 & 0.014 & 3.55 & 10.45 & 1.32 & 0.028 & 0.012 & 0.051 & 0.53 & 0.16 \\
Base Metal, DMR-249 Grade A & 0.30 & 0.110 & 0.05 & 1.05 & 1.65 & 0.06 & 0.05 & 0.30 & 0.40 & - \\
\hline
\end{tabular}

Table 2. Welding parameter for welding consumable.

\begin{tabular}{ccccccc}
\hline \multicolumn{2}{c}{ Filler } & \multicolumn{4}{c}{ Range of Process Parameter } \\
\hline Type & $\begin{array}{c}\text { Dia. } \\
(\mathbf{m m})\end{array}$ & Voltage/Current & Amperes (A) & Voltages (V) & $\begin{array}{c}\text { Travel Speeds } \\
(\mathbf{c m} / \mathbf{m i n})\end{array}$ & $\begin{array}{c}\text { Heat Inputs } \\
(\mathrm{KJ} / \mathrm{cm})\end{array}$ \\
\hline E2209-16 & 4.0 & DC-RP & $120.0-125.0$ & $22.0-25.0$ & $13.0-14.5$ & $12.2-12.9$ \\
\hline
\end{tabular}

\subsection{Solidification and Ferrite Prediction}

A traditional Schaeffler diagram showing the constitution of the DSS weld metal was plotted. This diagram assists to predict the type of microstructures in weld metals and parent materials. Chromium equivalent $\left(\mathrm{Cr}_{\mathrm{eq}}\right)$ is defined as the ferrite former or 
stabilizer, whereas nickel equivalent $\left(\mathrm{Ni}_{\mathrm{eq}}\right)$ is described as the austenite former or stabilizer. The solidification of primary austenite can occur when the ratio of $\mathrm{Cr}_{\mathrm{eq}}$ to $\mathrm{Ni}_{\mathrm{eq}}$ is below 1.25. Liquefaction cracking is believed to occur with the critical partitioning of impurities, such as sulfur and phosphorus [8,9]. According to Chakrabarti et al. [10], if the ratio of $\mathrm{Cr}_{\text {eq }}$ to $\mathrm{Ni}_{\text {eq }}$ is higher than 1.95, the solidification mode will be fully ferritic due to the strong diffusivity of chromium and molybdenum in the ferrite phase. The solidification and transformation sequence of the DSS microstructure is " $\mathrm{L} \rightarrow \mathrm{L}+\delta \rightarrow \delta \rightarrow \delta+\gamma$." The Schaeffer diagram can quantitatively forecast the microstructure in the weld metal based on the $\mathrm{Cr}_{\mathrm{eq}}$-to-Ni $\mathrm{Neq}_{\mathrm{eq}}$ ratio [11]. Equations (1) and (2) are used to obtain the weighting factors:

Austenite Stabilizing Element:

$$
\text { Nickel } \mathrm{Ni}_{\mathrm{eq}}=\% \mathrm{Ni}+30(\% \mathrm{C})+0.5(\% \mathrm{Mn})
$$

Ferrite Stabilizing Element:

$$
\text { Chromium } \mathrm{Cr}_{\text {eq }}=\% \mathrm{Cr}+\% \mathrm{Mo}+1.5(\% \mathrm{Si})+0.5(\% \mathrm{Nb})
$$

\subsection{Heat Treatment}

The PWHT process parameters involve three fundamental steps, which are heating, soaking, and cooling. The heating temperature from ambient to $315^{\circ} \mathrm{C}$ was considered an unrestricted parameter. Above $315^{\circ} \mathrm{C}$, heating was carried out using heating elements at a rate no greater than $335^{\circ} \mathrm{C}$ per hour divided by the maximum metal thickness in $\mathrm{mm}$. During the holding period, the differential soaking temperatures were maintained within $\pm 20^{\circ} \mathrm{C}$ upper and lower limits. The soaking time of PWHT was governed by wall-thickness, most of industrial code of standard requested for one (1) hour per $25 \mathrm{~mm}$, except for solid solution annealing temperature $\left(1050{ }^{\circ} \mathrm{C}\right)$, the soaking period was maintained at $2 \mathrm{~h}$. After soaking was completed, the cooling process was carried out at a rate no greater than $335^{\circ} \mathrm{C}$ per hour divided by the maximum metal thickness of the thicker part in mm until $315^{\circ} \mathrm{C}$. Air cooling test samples could only be removed from insulation blanket when cooling temperature has reached to $315^{\circ} \mathrm{C}$ whereas water quenching test samples were immediately quenched with running water at $33 \pm 2{ }^{\circ} \mathrm{C}$. Table 3 presented the information of soaking temperatures and cooling methods of test samples.

Table 3. Post weld heat treatment conditions.

\begin{tabular}{cc}
\hline $\begin{array}{c}\text { Sample } \\
\text { ID }\end{array}$ & Temperatures and Cooling Methods \\
\hline S1 & As-welded (without heat treatment) \\
S2 & at $350{ }^{\circ} \mathrm{C}$ with air cool \\
S3 & at $350{ }^{\circ} \mathrm{C}$ with water quench \\
S4 & at $3500^{\circ} \mathrm{C}$ with air cool \\
S5 & at $350{ }^{\circ} \mathrm{C}$ with water quench \\
S6 & at $350{ }^{\circ} \mathrm{C}$ with air cool and reheat at $1050{ }^{\circ} \mathrm{C}$ with water quench \\
S7 & at $350{ }^{\circ} \mathrm{C}$ with water quench and reheat at $1050^{\circ} \mathrm{C}$ with water quench \\
S8 & at $6500^{\circ} \mathrm{C}$ with air cool and reheat at $1050^{\circ} \mathrm{C}$ with water quench \\
S9 & at $650^{\circ} \mathrm{C}$ with water quench and reheat at $1050^{\circ} \mathrm{C}$ with water quench \\
\hline
\end{tabular}

\subsection{Macro Hardness}

The macro-hardness test ensures that the material quality and mechanical properties meet the standard requirements after surface treatment. In this study, Vickers hardness was used to measure the resistance of the material to indentation. The Vickers hardness test gives accurate measurements for ceramic materials, alloyed steels, and weld metals. In this test, the material surface is indented using standard loads applied for a specified length of time. The diagonal length of the impression is proportional to the driving force of the pyramid slope area of the indentation. The pyramid has a standard square base 
and a pyramidal indenter with an impression angle of $136{ }^{\circ} \mathrm{C}$. A load indenter at $10 \mathrm{kgf}$ is released and slowly applied onto the test specimen surface, without any vibration, at a temperature of $(25 \pm 5){ }^{\circ} \mathrm{C}$. The load is held up for $10-15 \mathrm{~s}$ before it automatically returns to its original (or neutral) position. The average of two mean readings is then taken to calculate the hardness value. The two indentation diagonal lengths should be limited to not more than $5 \%$ of the flat surface. At least three readings must be taken-from the weld metal, the heat-affected zone, and the base material [12].

\subsection{Microstructure Charaterization}

Metallographic examination and physical property analysis were carried out based on the ASTM A923-Method A [13]. A quick analysis of the DSS microstructure detrimental phase was done to determine the resistance of the material. Moreover, the detrimental phase of the weld overlay was investigated using a scanning electron microscope (SEM). Plane grinding was done using silicon carbide with a reduction abrasive grit size 240 until $3 \mu \mathrm{m}$ was achieved in the final polishing process [14]. The etching process for the metallographic test samples was electro etching done in $10 \% \mathrm{NaOH}$ solution per $100 \mathrm{~g}$ of the sample using. The distilled water was changed from $1-3 \mathrm{~V}$ dc for $15 \mathrm{~s}$ to generate better differences in the austenite and ferrite phases. The etched microstructure was metallurgically evaluated with a light microscope (ML) and a field emission scanning electron microscope (FE-SEM), both of which give a high-quality image of the interface between the weld overlay, the base material, the secondary phase, the retained austenite (light phase), and the ferrite (in the dark phase) [13].

\subsection{Analysis of Chemical Dilution}

The DSS-CRA weld overlay works well with low-alloy or high-tensile carbon steel depending on the extent of dilution [15]. In cladding or weld overlay applications, the dilution effect needs to be kept at a minimum to maintain the original alloy elements and to ensure the cladding retains its corrosion and wear resistance [16]. The concept of dilution is shown in the schematic illustration of Figure 1. The weld overlay alloying elements in the fusion zone are affected by the concentration and the dilution of chemical elements in the area of the weld metal $\left(A_{\mathrm{fm}}\right)$ and the base metal area $\left(A_{\mathrm{bm}}\right)$.

$$
\text { Dilution (D) }=\frac{A_{\mathrm{bm}}}{A_{\mathrm{bm}}+A_{\mathrm{fm}}}
$$

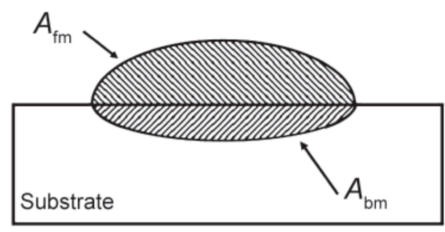

Figure 1. Illustration of dilution of base metal and filler metal in fusion weld.

Dilution (D) can be measured based on the amount of substrate material mixed with the weld metal in the fusion zone. In most applications, it is crucial to control the chemical dilution between the two materials to produce the required microstructure and properties for the intended service. The metallographic microstructure of the transition zone can be evaluated using a high magnification optical light microscope. The morphological microanalysis was done using FE-SEM, and the chemical alloying elements were determined using a SPECTROLAB metal analyzer (Kleve, Germany). The weld bead dilution indicating the chemical composition was estimated at 30\%. The methodology of calculation for the first layer weld deposit was based on $70 \%$ welding bead and $30 \%$ base metal. The chemical composition for the dilution of the second layer remained the same, at 30\%. The resulting chemistry of the second layer deposit (30\% of 30\%) was $9 \%$ base metal and (100\%-9\%) or $91 \%$ welding bead. The estimated specific chemical elements of each weld layer are presented in Table 4. 
Table 4. Prediction dilution for alloying elements in each weld layer.

\begin{tabular}{ccccccccc}
\hline Weld Metal & Dilution & $\mathbf{C}$ & $\mathbf{~ N i}$ & $\mathbf{N}$ & $\mathbf{M n}$ & $\mathbf{C r}$ & Mo & Si \\
\hline 1st Layer & $30.0 \%$ & 0.044 & 7.62 & 0.14 & 1.42 & 16.47 & 2.49 & 0.49 \\
2nd Layer & $30.0 \%$ & 0.026 & 9.60 & 0.17 & 1.35 & 21.32 & 3.22 & 0.52 \\
\hline
\end{tabular}

\section{Results and Discussion}

\subsection{The Effect of PWHT on Mode of Solification}

The solidification mode and transformation weld overlay performed under different heat treatment conditions were studied. The austenite grain precipitate in the solid-state was determined from the nucleation and growth along the ferrite boundaries. The amount of austenite and ferrite precipitation in the DSS weld deposits strongly depends on the amount of chemical composition and the number of heat cycles. The solidification modes can be determined by using chromium equivalent $\left(\mathrm{Cr}_{\mathrm{eq}}\right)$ and nickel equivalent $\left(\mathrm{Ni}_{\mathrm{eq}}\right)$ values as shown in Table 5. In the current experimental work, the solidification mode has been categorized in ferrite mode with austenite and ferrite microstructures at the ratio of $\mathrm{Cr}_{\mathrm{eq}} / \mathrm{Ni}_{\mathrm{eq}}$ in the range between 2.24 and 2.33 with red highlighted as indicated in Figure 2.

Table 5. Shows the solidification mode and microstructure of weld overlay.

\begin{tabular}{cccccc}
\hline Specimen & $\mathbf{C r}_{\mathbf{e q}}$ & $\mathbf{N i}_{\mathbf{e q}}$ & $\mathbf{C r}_{\mathbf{e q}} \mathbf{\mathbf { N i } _ { \mathbf { e q } }}$ & Solidification Mode & Microstructure \\
\hline 1 & 22.51 & 9.93 & 2.27 & Ferrite & $\mathrm{A}+\mathrm{F}$ \\
2 & 22.63 & 9.88 & 2.29 & Ferrite & $\mathrm{A}+\mathrm{F}$ \\
3 & 22.55 & 9.99 & 2.26 & Ferrite & $\mathrm{A}+\mathrm{F}$ \\
4 & 22.61 & 9.92 & 2.28 & Ferrite & $\mathrm{A}+\mathrm{F}$ \\
5 & 22.73 & 9.86 & 2.31 & Ferrite & $\mathrm{A}+\mathrm{F}$ \\
6 & 22.19 & 9.89 & 2.24 & Ferrite & $\mathrm{A}+\mathrm{F}$ \\
7 & 22.47 & 9.95 & 2.26 & Ferrite & $\mathrm{A}+\mathrm{F}$ \\
8 & 23.19 & 9.96 & 2.33 & Ferrite & $\mathrm{A}+\mathrm{F}$ \\
9 & 22.76 & 9.96 & 2.29 & Ferrite & $\mathrm{A}+\mathrm{F}$ \\
\hline
\end{tabular}

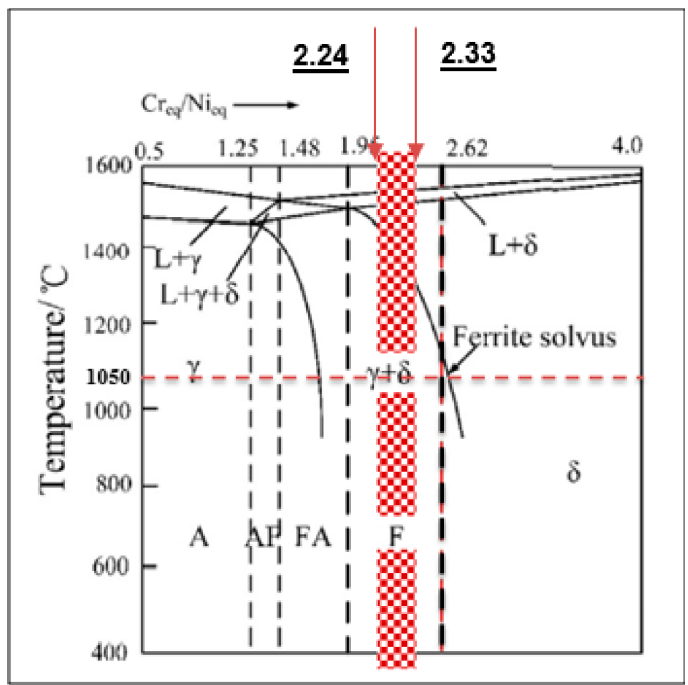

Figure 2. The DSSs solidification modes in the ternary Fe-Cr-Ni Section.

\subsection{Microstructure of Weld Deposits}

In this research work, isothermal heat treatments in the range $350-1050{ }^{\circ} \mathrm{C}$ for various holding times and different cooling rates have been applied on duplex stainless steel weld overlays to study the kinetic of alpha embrittlement, carbide, chromium nitride, chi and sigma phase precipitation. Figure $3 a-i$ show the micrograph of cross sections 
of the weld metals which present an austenite-ferrite phase microstructure. Sample No. 1 (as welded), shown in Figure 3a, revealed two phase microstructures in the austeniteferritic matrix, where it can be observed that the amount of austenite phase formation was greater that of ferrite phase which was indicated by a higher pitting corrosion resistance. Samples No. 2 and 3 (Figure $3 b, c$ ) had undergone PWHT at $350{ }^{\circ} \mathrm{C}$ and indicated that the grain boundary austenite (GBA) and widmanstatten austenite (WA) had slightly decreased. Samples No. 4 and 5 showed that the volume fraction of ferrite was slightly deceased in the weld metal as shown in Figure 3d,e, which might be due to lots of precipitated ferrite phase that was dissolved into the gamma $(\gamma)$ phase. By increasing the solution anneal temperature to $1050{ }^{\circ} \mathrm{C}$, numerous intra-granular austenite grains structures were revealed, whereas the amount ferrite phases were further reduced. The micrographs in Figure 3f,i depict that austenite grains did not show any favorable growth direction. The indications have shown that the entire contents of austenite in weld metal and heat affected zone are increased after conducting solution annealing treatment followed by rapid quenching in water in order to avoid the sensitizing temperature zone varying from $800{ }^{\circ} \mathrm{C}$ to $500{ }^{\circ} \mathrm{C}$.

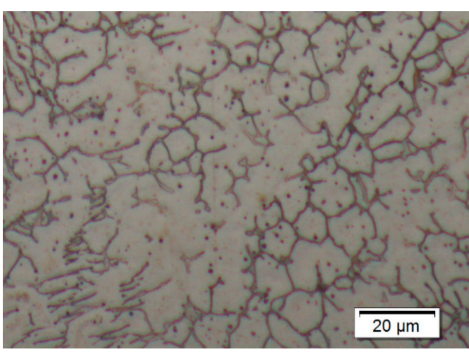

(a) As-welded (No PWHT)

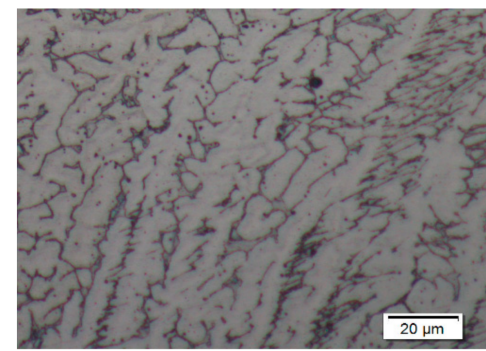

(d) PWHT @ $650{ }^{\circ} \mathrm{C}(\mathrm{AC})$

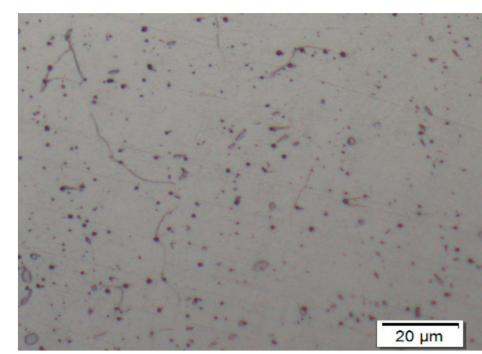

(g) PWHT @ $350{ }^{\circ} \mathrm{C}$ (WQ)

+ Reheat@ $1050{ }^{\circ} \mathrm{C}(\mathrm{WQ})$

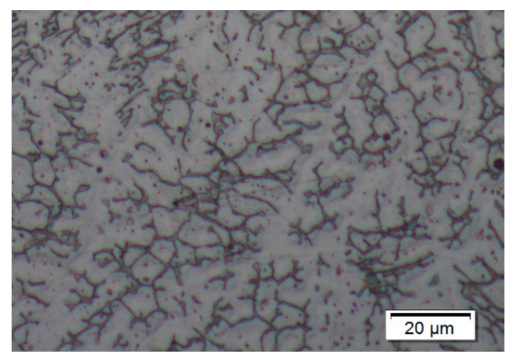

(b) PWHT @ $350{ }^{\circ} \mathrm{C}(\mathrm{AC})$

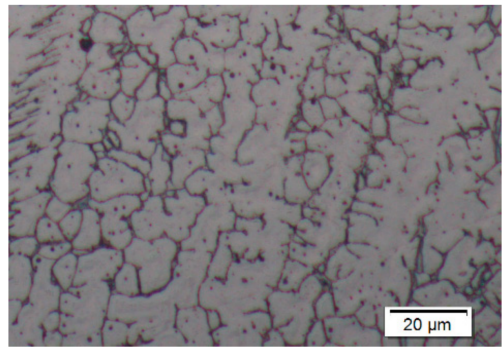

(e) PWHT @ $650{ }^{\circ} \mathrm{C}(\mathrm{WQ})$

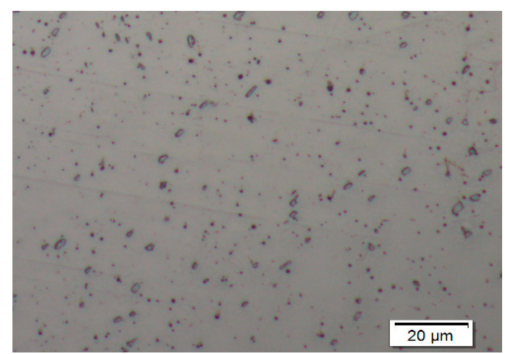

(h) PWHT $650{ }^{\circ} \mathrm{C}(\mathrm{AC})$

+ Reheat @ $1050{ }^{\circ} \mathrm{C}(\mathrm{WQ})$

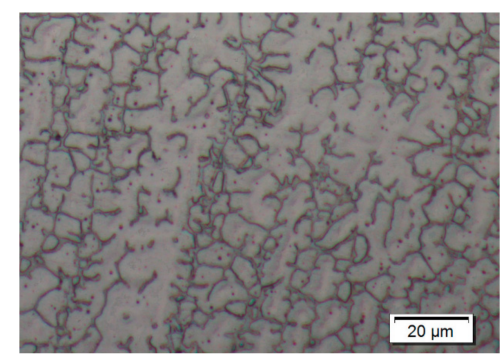

(c) PWHT @ $350{ }^{\circ} \mathrm{C}(\mathrm{WQ})$

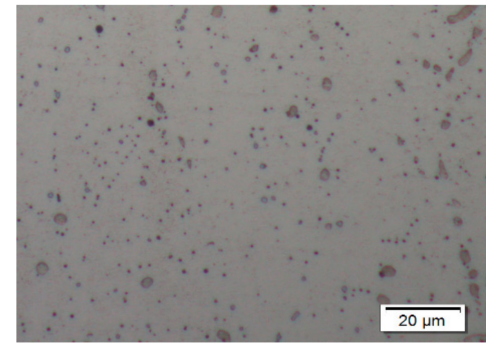

(f) PWHT @350 ${ }^{\circ} \mathrm{C}(\mathrm{AC})$

+ Reheat@ $1050{ }^{\circ} \mathrm{C}(\mathrm{WQ})$

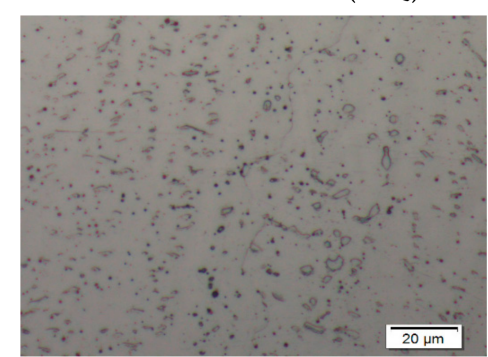

(i) PWHT $350{ }^{\circ} \mathrm{C}$ (WQ)

+ Reheat $1050{ }^{\circ} \mathrm{C}(\mathrm{WQ})$

Figure 3. SEM Image of at fusion zone with three different heat treatments (Dark phase ferrite, white phase-austenite). 


\subsection{Weld Metal Dilution}

The alloying elements of the DSS weld overlay were greatly influenced by the mixing of the filler and the base metal compositions, especially the dilution between the two dissimilar metals (i.e., DSS and carbon steel). Several factors should be considered when determining dilution effects, such as heat input, polarity, cooling rates, electrode size, electrode stick-out, type of shielding, and bead spacing. All these variables will influence the dilution of the weld overlay. The dilution of weld metal chemical composition was estimated using a 30\% approach, as confirmed by Jagesvar et al. [15].

In this research study, the locations of actual chemical data are obtained at $3 \mathrm{~mm}$ from the fusion line to indicate/determine the alloying element segregation/migration. The geometrical plotting method was employed to estimate the area of dilution between the two materials. Figure 4 shows the actual dilutions obtained in the range of $30.98 \%$ and $33.14 \%$ for as-weld and heat treated samples nos. 1 to 5 . The samples nos. 6 to 9 , have undergone high temperature heat treatment at $1050{ }^{\circ} \mathrm{C}$ with rapid water quenching and their micrographs showed the disappearance of the heat affected zone therefore dilution was invisible.

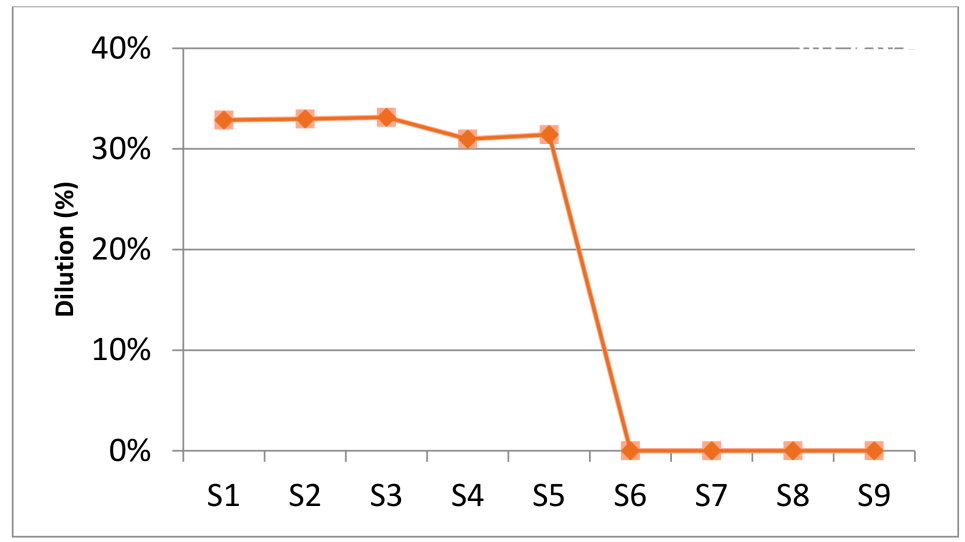

Figure 4. Comparison of dilution with the effect of heat treatment processes.

\subsection{Chemical Elements Distribution}

The partitioning of the major chemicals elements such as carbon, chromium, nickel, molybdenum and nitrogen which can contribute intermetallic phases (sigma, chi, nitrides, carbides etc.) in conventional duplex stainless steels have been measured for various post weld heat treatment and solid solution annealing temperatures.

\subsubsection{Carbon (C)}

Carbon is the main chemical element to provide strength for austenite grain structures, particularly at elevated temperatures and to prevent solidification cracking. Although carbon is an austenite-former, this chemical element is limited to the lowest practicable levels to prevent the possible formation of $\mathrm{M}_{23} \mathrm{C}_{6}$ carbides in the ferrite phase or at the grain boundaries. The carbon content in the weld metals as shown in Figure $5 \mathrm{a}$ indicated higher values than predicted, which might due to the carbon migration from the base metal to the weld metal during the heat input cycle. As-welded values ranged from $0.030 \mathrm{wt} . \%$ to $0.034 \mathrm{wt} . \%$. After PWHT at $350{ }^{\circ} \mathrm{C}$, the carbon alloying element slightly increased from $0.031 \mathrm{wt} . \%$ to $0.036 \mathrm{wt} . \%$. PWHT at $650{ }^{\circ} \mathrm{C}$ indicated quite extensive carbon migration from the base metal, with the results showing a significant increased from 0.032 to $0.038 \mathrm{wt} . \%$. Carbon has a high affinity to form carbide precipitates with chromium between the grain boundaries in the fusion zone. Excessive carbon content can introduce undesirable precipitates within the ferrite phase, such as carbides $\left(\mathrm{M}_{7} \mathrm{C}_{3} / \mathrm{M}_{23} \mathrm{C}_{6}\right)$. 


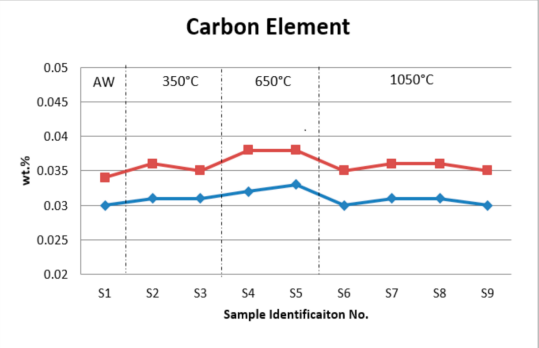

(a) Carbon contents in weld metals-FL $3 \mathrm{~mm}$

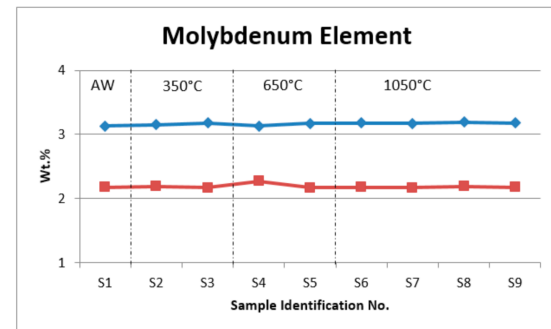

(c) Molybdenum contents in weld metals- FL $3 \mathrm{~mm}$

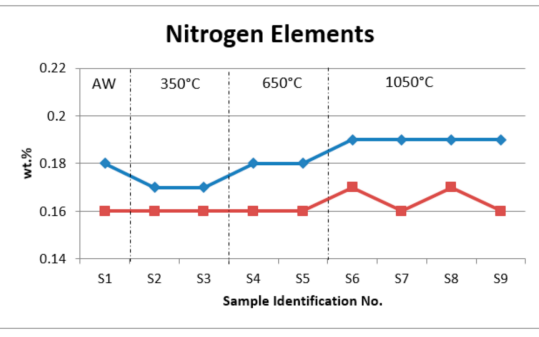

(e) Nitrogen contents in weld metals-FL $3 \mathrm{~mm}$

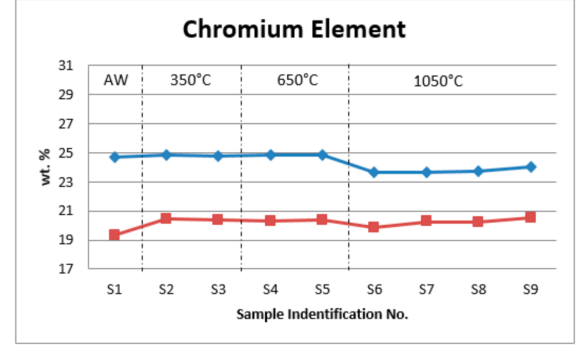

(b) Chromium contents in weld metals-FL $3 \mathrm{~mm}$

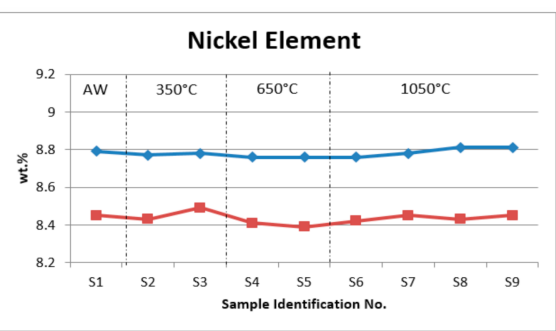

(d) Nickel contents in weld metals-FL $3 \mathrm{~mm}$

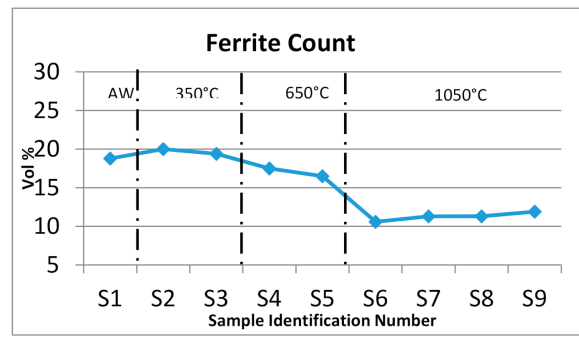

(f) Ferrite count in weld metals-FL $3 \mathrm{~mm}$

Figure 5. Chemical elements and ferrite counts for as-welded and heat treated samples.

\subsubsection{Chromium $(\mathrm{Cr})$}

This is a main chemical component that confers pitting corrosion resistance protection to steels with a minimum content of $20 \mathrm{wt} . \%$. It also promotes ferrite phase formation and increases the strength in solid solution, however an extremely high content can result in low ductility and inferior toughness. The as-welded sample showed chromium contents ranging from $20.33 \mathrm{wt}$.\% to $24.67 \mathrm{wt} . \%$. PWHT samples No. 2 to 5 showed a slightly high chromium content in between $20.34 \mathrm{wt} . \%$ and $24.87 \mathrm{wt} . \%$, respectively, because of the higher temperature of the heat treatment and the aging time that could cause the chromium content in the Fe-rich phase to progressively increase during the ferrite decomposition. However, the selected PWHT samples No. 6 to 9 were subjected to a reheating process at solid solution temperature $\left(1050^{\circ} \mathrm{C}\right)$ with 2 -h soaking time and immediately quenched with water. The results showed consistently low chromium content at $19.88 \mathrm{wt} . \%$ and $23.68 \mathrm{wt} . \%$ as indicated in Figure $5 b$, which was due to the solid-state phase transformation from austenite to alpha $(\alpha)$ ferrite, the higher volume fraction of ferrite prevents the chromium and molybdenum from spreading over a greater region and becoming diluted. It has also been reported by Guo et al. [17] that the content of chromium decreased in the ferrite phase and slightly improved in the austenite phase, with the same solution annealing temperature.

\subsubsection{Molybdenum (Mo)}

Molybdenum is usually added as a secondary alloying element, especially to improve pitting corrosion resistance in chloride environments and strengthen the steel at elevated temperature. The minimum content of molybdenum shall be controlled within $4 \mathrm{wt} . \%$ higher amount of molybdenum will cause detrimental due to formation of intermetallic precipitates. The test results as shown in Figure $5 \mathrm{c}$ have indicated the contents are in between $2.17 \mathrm{wt} . \%$ and $3.19 \mathrm{wt} . \%$, which approximately represents a $10 \%$ to $38 \%$ reduc- 
tion from the original electrode chemical composition (3.53 wt.\%) due to dilution effects. Overall molybdenum has shown consistent results, except for samples No. 4 and 5 which underwent stress relief heat treatments and have shown a small increment in the lower range values. According to Kai and Sie [18], a higher molybdenum content has a greater potential to form the sigma and chi phase in DSS as a result of post-weld heat treatment.

\subsubsection{Nickel}

This element is commonly added into DSS to promote formation of the austenite phase matrix and improve the fracture toughness at lower temperatures. The results showed consistent lower values, as indicated in Figure 5d, in between $8.42 \mathrm{wt} . \%$ and $8.81 \mathrm{wt} . \%$, although the heat-treated samples showed slight fluctuations. The nickel content in the weld metal was reduced from $15 \%-19 \%$ of its original value of $10.44 \mathrm{wt} . \%$, which is possibly due to the dilution effect of the welding heat input as well as the heat treatment process, which promotes the formation of secondary austenite. Nickel is a good solution strengthener to improve impact toughness for all kinds of stainless steels; it reduces the ductile to brittle fracture transition temperature (DBTT).

\subsubsection{Nitrogen $(\mathrm{N})$}

Nitrogen's primary function is to improve and stabilize the formation of the austenite phase. It is normally added in DSS and controlled within the range of 0.08 and $0.35 \mathrm{wt} . \%$. The as-welded samples indicated values of $0.16 \mathrm{wt} . \%$ and $0.18 \mathrm{wt} . \%$. PWHT $350{ }^{\circ} \mathrm{C}$, samples No. 2 and 3 showed the lowest nitrogen content at $0.16 \mathrm{wt} . \%$ and $0.17 \mathrm{wt} . \%$, whereas, samples No. 4 and 5 subjected to PWHT $650{ }^{\circ} \mathrm{C}$ revealed similar values as welded sample. The highest obtained values of nitrogen were from $0.16 \mathrm{wt} . \%$ to $0.19 \mathrm{wt} . \%$ for the solid solution annealing samples No. 6 to 9 which enhance the corrosion properties as referred in Figure 5e.

\subsubsection{Ferrite (Fe) Count}

Most of oil and gas industries have stated the average ferrite content should be in between $40-60 \%$ by volume for the weld metal and heat affected zone regions for duplex stainless steel [19]. DSS weld overlays with local heat treatments have therefore not been critically studied in such details [20]. In this research study, the results had revealed that ferrite count determination in the region of weld metal overlay were decreased with high temperatures, as referred in Figure $5 f$. The welded sample indicated ferrite contents of $18.8 \pm 2.14$ vol. $\%$ PWHT $350{ }^{\circ} \mathrm{C}$ with air cooling resulted in a slightly higher ferrite content at $20 \pm 1.78 \mathrm{vol} . \%$ as compared to the water quenching technique, which produced a marginally lower ferrite count $19.4 \pm 2.05$ vol.\%. Similarly, with PWHT $650{ }^{\circ} \mathrm{C}$ air cooling also resulted in a lower ferrite content of $17.5 \pm 1.57 \mathrm{vol} . \%$, whereas the waterquenching technique showed a reduction in ferrite value of $16.3 \pm 1.34 \mathrm{vol} . \%$, due to the fact slow cooling rates are more favorable to austenite formation due to the sufficient time for nucleation growth. However, the amount of ferrite in the weld metals decreased considerably from $10.6 \pm 1.36 \mathrm{vol} . \%$ to $11.9 \pm 0.82 \mathrm{vol} . \%$ the increment of temperature to solution annealing at $1050{ }^{\circ} \mathrm{C}$. If appropriate time were given for austenite formation, an optimal equilibrium fraction for the weld area could be achieved. Figure 3 shows the ferrite content in the area of the weld metal overlay under the influence of different heat treatments.

\subsection{Macro-Hardness}

The macro-hardness measurement of the weld overlay cross-section profile ass shown in Figure 6. The weld profile can be categorized into three characteristic regions: (a) weld metal zone (E2209-16); (b) heat affected zone (HAZ); and (c) base metal region (DMR 249A). The macro hardness of the DSS weld overlay was obtained in the range between 193 $\mathrm{Hv}$ and $241 \mathrm{Hv}$, as displayed in Figure 7. Likewise, HAZ showed lower macro-hardness values between $197 \mathrm{Hv}$ and $241 \mathrm{Hv}$ while the base metal indicated a higher macro-hardness, 
ranging from $204 \mathrm{Hv}$ to $376 \mathrm{Hv}$, due to the different heat treat temperatures and cooling effects applied. The hardness of the first layer of the treated and non-treated weld overlay test samples was slightly higher than that of the 2nd layer (weld cap). This slight increase in hardness could be due to heat treatment, which caused carbide coarsening and precipitation. The weld metal hardness values increased after being subjected to PWHT at $350{ }^{\circ} \mathrm{C}$ and $650{ }^{\circ} \mathrm{C}$ because of the refining of the grains and the slight increment in the ferrite volume fractions, which were detected in the zone of fusion, as highlighted in Figure $5 \mathrm{f}$. The weld metal for samples 6 to 9 was subjected to a solution annealing temperature of $1050{ }^{\circ} \mathrm{C}$ with water quenching. The test results showed consistent low hardness values in the range of (192-204) Hv at the weld overlay and HAZ regions. However, the hardness values substantially increased from $364 \mathrm{Hv}$ to $376 \mathrm{Hv}$ at the base metal, with this higher hardness value appearing to have larger grains and a noticeably equiaxed ferritic structure as well as the presence of a large amount of martensite.

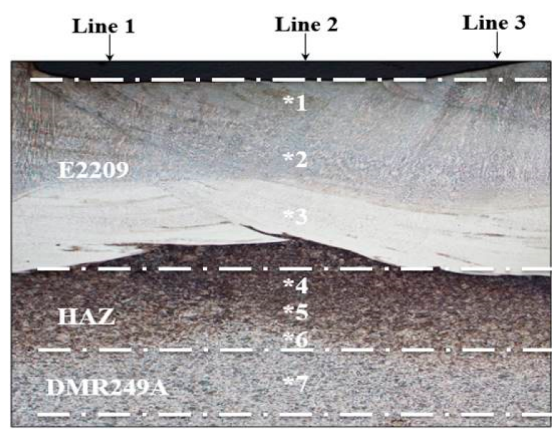

Figure 6. Micro-hardness test location at the cross-section.

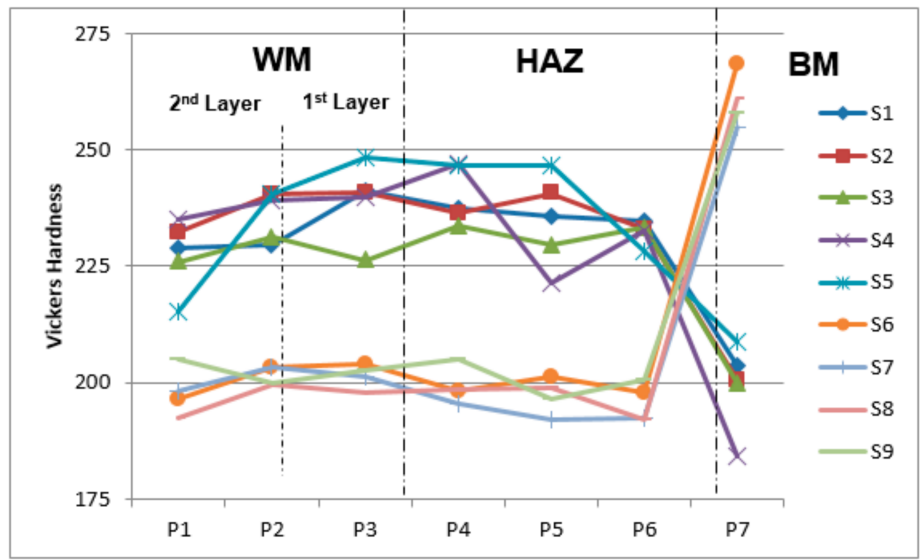

Figure 7. Comparison of macro-hardness in the cross-section area.

\section{Conclusions}

In this research work, isothermal heat treatments in the range $350-1050{ }^{\circ} \mathrm{C}$ with various holding times and different cooling rates have been performed on DSS weld overlays on carbon steel substrates. The solidification mode was categorized as ferrite mode with austenite and ferrite microstructures displaying $\mathrm{Cr}_{\mathrm{eq}} / \mathrm{Ni}_{\mathrm{eq}}$ ratios in between 2.24 and 2.33.

Micrographs (as welded samples) showed two phase microstructures of the DSS weld metal, as compared to post-weld heat treatment samples, where the austenite phase formation is greater than that of ferrite phase. Generally, after PWHT at $350{ }^{\circ} \mathrm{C}$, the microstructures showed a slight reduction in austenite phase. After PWHT at $650{ }^{\circ} \mathrm{C}$, micrographs showed a further reduction in the volume fraction of ferrite due to precipitation of ferrite phase dissolved into gamma phase. A solution annealing temperature of $1050{ }^{\circ} \mathrm{C}$ produced numerous intra-granular austenite grains structures and the amount ferrite phases was significantly reduced. 
Based on industrial practice, SMAW process dilution is taken as 30\%. The produced dilution of the DSS weld overlay was $32.87 \%$ for as-welded sample, a slightly increment of about $1 \%$ for PWHT at $350{ }^{\circ} \mathrm{C}$ and a small reduction of approximately $2 \%$ was observed for PWHT at $650{ }^{\circ} \mathrm{C}$. Solution annealing temperature at $1050{ }^{\circ} \mathrm{C}$ with water quenching revealed the disappearance of the heat affected zone in micrographs.

A slight increment in hardness for the first layer was observed as compared to the 2nd layer of the weld deposits and the weld metal hardness values increased after conducting PWHT. The solid solution annealing produced consistently low hardness values at the WM and HAZ and was unfavorable for base metal and the hardness increased substantially and produced larger grains, noticeable in the equiaxed ferritic structure, together with the occurrence of a large quantity of martensite.

The major alloying elements $(\mathrm{C}, \mathrm{Mo}, \mathrm{Cr}, \mathrm{Ni}, \mathrm{N}$, and $\mathrm{Fe})$ were analyzed, as these elements can contribute to the formation of intermetallic phases. The results showed that $\mathrm{C}$ and $\mathrm{Cr}$ content slightly increased as a result of PWHT, except for solid solution annealing, Mo showed consistently low content due to dilution effects. Ni maintained a higher content, although the heat-treated samples showed slight fluctuations. Nitrogen produced consistent values as recommended to prevent critical nitride precipitation.

Author Contributions: The study topic was proposed by B.-M.S.; B.-M.S. and S.-H.T. organized and wrote the first draft of the paper; B.-M.S. conducted the research and drafted the methodology; S.-H.T., M.A. and E.-N.T.J. took part in the validation and analysis of the experimental tests. All coauthors contributed to manuscript. All authors have read and agreed to the published version of the manuscript.

Funding: This research received no external funding.

Acknowledgments: The open access preparations of this article were funded by the Research Centre of University Putra Malaysia.

Conflicts of Interest: The authors declare no conflict of interest.

\section{References}

1. Shamanth, V.; Ravishankar. Dissolution of Alpha Prime Precipitates in Thermally Embrittled S2205 Duplex Steels during Reversion Heat Treatment; Elsevier: Amsterdam, The Netherlands, 2015; pp. 297-303.

2. Mohammed, A.M.; Kulkarni, A.S.; Sathiya, P.; Sunkulp, G. The Impact of Heat Input on the Strength, Toughness, Microhardness, Microstructure and Corrosion Aspects of Friction Welded Duplex Stainless Steel Joints. J. Manuf. Process. 2015, 18, 92-106.

3. Abbas, E.; Keyvan, R.; Morteza, S. Tribocorrosion Behavior of Overlay Welded Super Duplex Stainless Steel Ii Chloride Medium. J. Biol. Tribo Corros. 2015, 1, 1-15.

4. American Society of Mechanical Engineers. ASME B31.3 Code for Pressure Piping_Pressure Piping; American Society of Mechanical Engineers: New York, NY, USA, 2016; Clause 331.

5. American Society of Mechanical Engineers. ASME VIII Code for Construction of Pressure Vessel; American Society of Mechanical Engineers: New York, NY, USA, 2017; Clause UG 85.

6. International Molybdenum Association. Practical Guidelines for the Fabrication of Duplex Stainless Steels; International Molybdenum Association: London, UK, 2015; p. 11, ISBN 979-1-907470-09-7. Available online: http://www.imoa.info/downloads/brochures_ articles.php (accessed on 26 September 2016).

7. Maria, E.R.C.; Sandra, N.; Carlos, A.D.R.; Sebastião, E.k.; Neide, A.M. Effect of Cooling Rate on the Corrosion Behavior of As-Cast SAF 2205 Duplex Stainless Steel After Solution Annealing Treatment. Mat. Res. 2015, 18. [CrossRef]

8. Tavares, S.S.M.; Pardal, J.M.; Martins, T.R.B.; Da Silva, M.R. Influence of Sulfur Content on the Corrosion Resistance of 17-4PH Stainless Steel. J. Mater. Eng. Perform. 2017, 26, 2512-2519. [CrossRef]

9. Kook, S.B.; Seong, H.P.; Sang, K.A. Evaluation of Weld Metal Hot Cracking Susceptibility in Superaustenitic Stainless Steel. Met. Mater. Int. 2013, 19, 1267-1273.

10. Chakrabarti, B.; Hrishikesh, D.; Santanu, D.; Tapan, P. Effect of Process Parameters on Clad Quality of Duplex Stainless Steel Using GMAW Process. Trans. Indian Inst. Met. 2014. [CrossRef]

11. Kchaou, Y.; Haddar, N.; Hénaff, G.; Pelosin, V.; Elleuch, K. Microstructural, Compositional And Mechanical Investigation of Shielded Metal Arc Welding (SMAW) Welded Superaustenitic UNS N08028 (Alloy 28) Stainless Steel. Mater. Des. 2014, 63, 278-285. [CrossRef]

12. British Standard. Metallic Materials, Vickers Hardness Test, BS EN ISO 6507-1; British Standard: London, UK, 2018.

13. ASTM A923. Standard Test Methods for Detecting Detrimental Intermetallic Phase in Duplex Austenitic/Ferritic Stainless Steels; ASTM International: West Conshohocken, PA, USA, 2014. 
14. Marques, M.J.; Ramasamy, A.; Batista, A.C.; Nobre, J.P.; Loureiro, A. Effect of heat treatment on microstructure and residual stress fields of a weld multilayer austenitic steel clad. J. Mater. Process. Technol. 2015, 222, 52-60. [CrossRef]

15. Jagesvar, V.; Ravindra, V.T. Effect of Welding Processes and Conditions on The Microstructure, Mechanical Properties and Corrosion Resistance of Duplex Stainless Steel Weldments. A review. J. Manuf. Process. 2017, 25, 134-152.

16. Lemke, J.N.; Rovatti, L.; Colombo, M.; Vedani, M. Interrelation between macroscopic, microscopic and chemical dilution in hardfacing alloys. Mater. Des. 2016, 91, 368-377. [CrossRef]

17. Guo, Y.; Hu, J.; Li, J.; Liu, T.; Wu, T. Effect of Annealing Temperature on the Mechanical and Corrosion Behavior of a Newly Developed Novel Lean Duplex Stainless Steel. Materials 2014, 7, 6604-6619. [CrossRef] [PubMed]

18. Kai, W.C.; Sie, C.T. Effect of Secondary Phase Precipitation on the Corrosion Behavior of Duplex Stainless Steels. Materials 2014, 7, 5268-5304. [CrossRef]

19. Petronas Technical Standard. Welding of Pipeline and Related Facilities_CRA Clad or CRA Lined Pipe Materials, PTS 15.12.07; Petronas Technical Standard: Kuala Lumpur, Malaysia, 2014.

20. Field Welding of Duplex and Super Duplex Stainless Steel Pipelines (Amendments/Suppliments To API 1104), DEP 61.40.20.31; Design Engineering Practice: Kuala Lumpur, Malaysia, 2011. 